Sintese - Rev. de Filosofia

v. 29 N. 93 (2002): 103-115

\title{
A REFLEXÃO DE RICOEUR SOBRE O JUSTO*
}

Theresa Calvet de Magalhães F AF I CH / UFMG

Resumo: Do lugar filosófico do justo à prática da justiça (à prática judiciária), caracterizada por suas ocasiões (as circunstâncias ou ocasiōes da justiça, isto é, as situações de conflito às quais o direito dá a forma do processo), por suas vias e meios (os canais no plano institucional ou os canais da justiça; ou seja, o próprio aparelho judiciário que compreende não apenas um corpo de leis escritas, mas tribunais ou cortes de justiça, investidos da função de dizer 0 direito, juizes, isto é, pessoas reputadas independentes e encarregadas de pronunciar a sentença justa numa circunstância particular, e ainda 0 monopólio da coerção, a saber: o poder de impor uma decisão de justiça pelo uso da força pública), e por seu modo de argumentação: eis o percurso desta breve exposição.

Palavras-chave: Ética, Moral, Justiça.

Résumé: Du lieu philosophique du juste à la pratique de la justice (à la pratique judiciaire), caractérisée par les occasions (les circonstances) de la justice (c'està-dire les situations auxquelles le droit donne la forme du procès), par les voies et moyens de la justice (les canaux au plan institutionnel, c'est-à-dire l'appareil judiciaire lui-même comprenant non seulement un corps de lois écrites, mais aussi des tribunaux ou des cours de justice, investis de la fonction de dire le droit, des juges, c'est-à-dire des individus réputés indépendants et chargés de prononcer la sentence juste dans une circonstance particulière, et le monopole de la coercition, autrement dit, le pouvoir d'imposer une décision de la justice par l'emploi de la force publique), et par les arguments au niveau du discours de la justice: voici le parcours de cet exposé.

Mots clef: Ethique, Morale, Justice

* Conferência apresentada no Seminário Direito e Ética, promovido pelo Centro Acadêmico Afonso Pena da Faculdade de Direito da UFMG, Belo Horizonte, em 17 de novembro de 1999. Uma primeira versão deste texto foi apresentada na III Semana Filosófica, promovida pelo Diretório Acadêmico Dom Oscar Romero, Gestão 96/97, Instituto Santo Tomás de Aquino, Belo Horizonte, em 16 de setembro de 1996. 
m 1990, em Soi-même comme un autre ${ }^{1}$, Ricoeur já tinha delimitado o lugar filosófico do justo, ao justificar as três teses seguintes no que chamou, com ironia e modéstia (falsa modéstia ou não), de sua "pequena ética":

1) A prioridade da ética sobre a moral, isto é, a prioridade da visada da vida boa, com e para os outros, em instituições justas, sobre a norma moral;

2) A necessidade, no entanto, para a visada ética de passar pelo crivo da norma moral: essa passagem da ética à moral, com seus imperativos e suas interdições, é por assim dizer exigida pela própria ética, na medida em que o desejo da vida boa encontra a violência sob todas as suas formas; e

3) A legitimidade de um recurso da norma moral à visada ética, quando a norma conduz a conflitos para os quais não há outra saída a não ser a de uma sabedoria prática, à criação de decisões novas frente a casos difíceis: os hard cases do direito, da medicina ou da vida cotidiana.

Toda a exposição dessa "pequena ética" apoia-se sobre uma distinção entre ética e moral que nada, insiste sempre Ricoeur, nem na etimologia nem na história do uso destes termos autoriza. 0 termo ética vem do grego ["ethos é uma transliteração dos dois vocábulos gregos ethos (com eta inicial) e ethos (com épsilon inicial)" ${ }^{2}$ ], o termo moral vem do latim (Cícero), e ambos remetem à idéia de costumes (mores, o ethos na sua realidade histórico-social). Mas haveria uma nuança: ou a ênfase é dada ao que é estimado bom ou ao que se impõe como obrigatório. E isso permite a Ricoeur reservar - mas apenas por convenção - 0 termo ética "para a visada de uma vida realizada sob o signo das ações estimadas boas", e o termo moral "para o lado obrigatório, marcado por normas, obrigações, interdições caracterizadas ao mesmo tempo por uma exigência de universalidade e por um efeito de coerção" (Ricoeur, 1991a, p. 256). Nesta distinção entre visada da vida boa (visada ética) e obediência às normas (à norma moral), podemos facilmente reconhecer "a distinção entre duas heranças": a herança aristotélica ["a ética é caracterizada pela sua perspectiva teleológica (de telos, que significa fim)"]; e a herança kantiana ["a moral é definida pelo caráter de obrigação da norma e, portanto, por um ponto de vista deontológico (deontológico significando precisamente "dever")] $]^{3}$. Atento aos textos fundadores

1 Ver também Rıcoeur, 1991a, 256.

$2 \mathrm{~V}_{\mathrm{AZ}}, 1988,12$.

3 Ricoeur, 1991a, 256. Essa oposição entre uma abordagem teleológica e uma abordagem deontológica não resume, no entanto, a contribuição de Ricoeur à discussão do problema moral. Os estudos VII e VIII de Soi-même comme un autre, que tratam dos dois níveis do juízo moral regidos pelos predicados do bom 
dessas duas tradições - a Ética a Nicômaco, a Fundamentação da M etafísica dos Costumes e a Crítica da Razão Prática - , mas sem a necessidade de ser fiel à ortodoxia aristotélica ou kantiana, Ricoeur, ao defender em sua "pequena ética" as três teses acima mencionadas, estabelece uma relação de subordinação e de complementaridade entre essas duas heranças ${ }^{4}$.

\section{O lugar filosófico do justo}

A arquitetura dos três estudos que compõem essa "pequena ética" (ou seja, o sétimo estudo: "O si e a visada ética", o oitavo estudo: "O si e a norma moral", e o nono estudo de Soi-même comme un autre: "O si e a sabedoria prática") funda-se sobre o entrecruzamento de dois eixos, ou de dois percursos diferentes de leitura. O lugar filosófico do justo estaria situado no ponto de intersecção do eixo "horizontal", que é o da constituição dialógica da ipseidade, que Ricoeur opõe à simples mesmidade, para caracterizar a espécie de identidade que convém ao "soi", ao "si" 5, e do eixo "vertical", o da constituição hierárquica dos predicados que determinam as "avaliações fortes" da ação humana (o predicado bom e o predicado obrigatório).

Ricoeur insiste em partir da noção de "vida boa" ou do que Aristóteles chamava de "viver-bem", e que podemos chamar também "verdadeira

e do obrigatório, constituem apenas exercícios preparatórios ao confronto com as situações que Ricoeur liga globalmente ao trágico da ação (ilustrado pela Antígona de Sófocles). O nono estudo (o estudo mais importante) tem justamente por objetivo explicitar a estrutura do juízo moral em situação singular.

${ }^{4}$ A identidade no sentido de idem, isto é, como mesmidade [mêmeté, sameness, Gleichheit], também desdobra uma hierarquia de significações que são explicitadas em Soi-même comme un autre, no quinto e no sexto estudos: "A identidade pessoal e a identidade narrativa", "O si e a identidade narrativa". O grau mais elevado dessa hierarquia é a permanência no tempo, a que se opõe o diferente, no sentido de mutável ou variável.

${ }^{5}$ A identidade no sentido de ipse, ou seja, como ipseidade [ipséité, selfhood, Selbstheit], não implica - é essa a tese de Ricoeur - nenhuma asserção quanto a um pretenso núcleo não mutável da personalidade, nem mesmo quando a ipseidade apresentaria modalidades próprias de identidade. A identidade-ipse colocaria em jogo a dialética do si e do outro que si mesmo. Enquanto permanecemos no círculo da identidade-mesmidade, a alteridade do outro que si mesmo não apresenta nada de original: "outro" figura aí na lista dos antônimos de "mesmo", ao lado de "contrário, distinto, diverso ... ". I sso não ocorre com o par ipseidade-alteridade: uma alteridade que não é (ou não é apenas) de comparação, uma alteridade que seria constitutiva da própria ipseidade. Ao "como" do título de sua obra, Ricoeur quer ligar a significação forte de uma implicação - e não apenas a significação de uma comparação (si mesmo semelhante a um outro) - si mesmo enquanto ... outro (RICOEUR, 1990, 12-14). 
vida" - seja qual for a imagem que cada um se faz de uma vida plenamente realizada, esse coroamento seria o fim último de sua ação - , e ele acentua o modo gramatical dessa expressão tipicamente aristotélica. 0 modo gramatical da expressão "vida boa" é o do optativo, e não ainda o do imperativo. No seu sentido mais forte, trata-se de uma intenção ou desejo: "Que eu possa, que tu possas ... viver bem", e antecipamos o preenchimento desta intenção ou desejo de viver bem numa exclamação do tipo: "Feliz aquele que ...!". Se a palavra "desejo" ou "intenção" não é suficientemente forte, diz Ricoeur, ela pode ser substituída por cuidado (cuidado de si, cuidado do outro, cuidado da instituição) ${ }^{6}$. A vida ética é, portanto, "o desejo de uma plena realização pessoal com

${ }^{6}$ Cf. Rıcoeur, 1991a, 257. A vantagem maior de partir da noção de "vida boa" seria, segundo Ricoeur, a de não fazer diretamente referência à ipseidade sob a figura da estima de si. O termo "si", que Ricoeur associa ao de "estima" no plano ético fundamental, não se confunde com o eu [/e moi], ou seja, "com uma posição egológica que o encontro com o outro viria necessariamente subverter". O que é fundamentalmente estimável em si mesmo, diz Ricoeur, é não apenas "a capacidade de escolher segundo razões, de preferir isto àquilo, ou seja, a capacidade de agir intencionalmente", mas também "a capacidade de iniciativa", ou seja, a capacidade de começar alguma coisa no mundo ou de introduzir mudanças no curso das coisas. E, nesse sentido, a estima de si pode ser considerada como "o momento reflexivo da práxis: é ao apreciar nossas ações que nos apreciamos a nós mesmos como sendo o autor dessas ações, ou seja, como não sendo simples forças da natureza ou meros instrumentos" (RıcoeuR, 1991a, 257). Mas a questão é, então, a de "saber se a mediação do outro não é exigida no trajeto que vai da capacidade à efetuação". O segundo componente da visada ética - a "solicitude" - desdobra a dimensão dialogal implícita da estima de si. E é aqui que se esclarece retrospectivamente o privilégio dado ao si sobre o eu. O outro é realmente solicitado por uma reflexão sobre a ação? O outro é realmente exigido no trajeto da práxis? Trata-se de uma questão muito importante para Ricoeur, porque está ligada à possibilidade de uma teoria política e ao destino das teorias do direito natural: "Esta hipótese de um sujeito de direito constituído anteriormente a toda ligação societal só pode ser refutada se cortamos a sua raiz. Ora, a raiz é o desconhecimento do papel mediador do outro entre capacidade e efetuação". A amizade [ver aqui a referência a Aristóteles] pode, então, ser considerada como mediação entre a visada da "vida boa" (que se reflete na estima de si, virtude aparentemente solitária) e a justiça, "virtude de uma pluralidade humana de caráter político" (RICOEUR, 1990, 213). A idéia de amizade, que é "o primeiro desdobramento do desejo de viver bem", leva paralelamente ao primeiro plano a problemática da reciprocidade (aparentemente a reciprocidade só estaria completa na amizade, nessa relação mútua onde um estima o outro tanto quanto a si mesmo). Essa idéia do caráter mútuo da amizade tem, com efeito, "exigências próprias que nem uma gênese a partir do Mesmo ... nem uma gênese a partir do Outro ... conseguem eclipsar. Segundo a idéia de mutualidade, cada um ama o outro enquanto o que ele é". E é, portanto, já no plano ético, que a reciprocidade se impõe - esse "enquanto que" (enquanto o que o outro é), constitutivo da mutualidade (RıCOEUR, 1990, 215). O que a amizade e a mutualidade acrescentam à estima de si? A amizade acrescenta à estima de si "a idéia de mutualidade na troca entre humanos que se estimam cada um a si mesmos"; e o corolário da mutualidade, ou seja, a igualdade, já coloca a amizade no caminho da justiça, "onde a partilha de vida entre um pequeníssimo número de pessoas cede o lugar a uma distribuição de partes em 
e para os outros, sob a virtude da amizade, e, em relação com um terceiro, sob a virtude de justiça" (Ricoeur, 1995b, p. 142). Segunda esta leitura, a justiça é parte integrante do desejo de viver bem: o justo é primeiro objeto de desejo e se enuncia num optativo antes de enunciar-se num imperativo.

Mas para marcar aqui o lugar onde a questão da justiça pode ser encontrada, é necessário, logo de início, fazer uma distinção entre duas acepções distintas da noção de outro ou de outrem. O primeiro outro é o outro das relações interpessoais, o "tu" (o "você", o "toi"), ou o outro portador de um rosto, e não se confunde com o outro que é o terceiro, sujeito da justiça. À amizade - e a referência aqui é mais uma vez a Aristóteles, aos Livros VIII e IX da Ética a Nicômaco, isto é, ao seu tratado da amizade [philia] - enquanto "virtude emblemática dessa relação imediata ou de proximidade ao outro", Ricoeur opõe a virtude de uma pluralidade humana de caráter político, a justiça. 0 justo é caracterizado primeiro como uma figura do bom: "é o bom com e para um outro, para um outro que ... é o socius que encontro através das instituições; é o outro das instituições, e não o outro das relações interpessoais" (Ricoeur, 1995b, p. 142). A virtude de justiça se estabelece sobre uma relação de distância em relação ao outro, tão originária quanto a relação de proximidade, uma relação ao outro que seria por assim dizer imediatamente mediatizada pela instituição: o outro, segundo a amizade, é o "toi", 0 outro, segundo a justiça, é o "chacun", o cada um, parte de um sistema de distribuição.

A virtude de justiça aplica-se, em primeiro lugar, às instituições e, por instituições, Ricoeur entende, neste primeiro nível de sua investigação, "todas as estruturas do viver-junto de uma comunidade histórica, irredutíveis às relações interpessoais e, no entanto, ligadas a elas em um sentido notável que a noção de distribuição permite esclarecer"7. Cabe à justiça atribuir a cada um a sua parte. 0 "cada um" (o outro que é o terceiro) é, então, o destinatário de uma divisão justa.

Ricoeur já tinha encontrado esse "chacun" ("cada um") naquelas situações exemplares que provocaram sua indignação contra a injustiça quando era jovem: divisões desiguais que ele considerava como inaceitáveis; promessas não cumpridas que abalaram pela primeira vez a confiança inocente que depositava na palavra [dada] sobre a qual, era o que aprenderia mais tarde, se apóiam todas as trocas, todos os con-

uma pluralidade na escala de uma comunidade política histórica" (RICOEUR, 1990, 220). O viver-bem não se limita às relações interpessoais: ao analisar o terceiro componente da visada ética (a visada da vida boa em instituições justas), a investigação de Ricoeur trata justamente da instituição como ponto de aplicação da justiça e da igualdade como conteúdo ético do sentido da justiça.

7 Ricoeur, 1991a, 259; ver também ID., 1990, 264 e 227. 
tratos, todos os pactos; e as punições que Ihe pareciam sem proporção com a falta cometida ou os elogios que eram dados arbitrariamente, segundo ele, aos outros, ou seja, o caso de retribuições a seu ver não merecidas - "tantas circunstâncias institucionais, no sentido amplo do termo, onde a justiça se anuncia como distribuição justa". A igualdade, não importa a maneira como a modulamos, diz Ricoeur, é no que diz respeito à vida das instituições, o que a amizade é para as relações interpessoais. Na medida em que o campo de aplicação da igualdade é a pólis, a justiça acrescenta à amizade "a comunidade histórica regida pelo Estado e, idealmente, toda a humanidade" (Ricoeur, 1991b, p. 182, nota 3).

O caso das instituições judiciárias é, a esse respeito, particular, mas este caso é justamente considerado por Ricoeur como sendo muito favorável a uma determinação mais exata do cada um segundo a instituição (Ricoeur, 1995a, p. 15). Com a instituição do tribunal, diz ele,

"o processo confronta partes que são constituídas "outras" pelo procedimento judiciário; ... a instituição encarna-se no personagem do juiz, que ... é o operador da justa distância que o processo institui entre as partes. (...) , unicamente na figura do juiz que a justiça se faz reconhecer como" - para usar aqui a expressão de John Rawls [em A Theory of Justice, 1971] - "primeira virtude das instituições sociais" (Ricoeur, 1995a, p. 15).

Em Soi-même comme un autre, Ricoeur achou importante dar atenção ao estado inicial em que a justiça é ainda uma virtude, isso no trajeto do desejo de uma vida boa - o que, aliás, consiste em admitir que ela contribui a orientar a ação humana para uma plena realização, uma perfeição - , e onde o sentido do injusto precede, pela sua lucidez, os argumentos dos juristas e dos políticos ${ }^{8}$. Não poderíamos já discernir na indignação, pergunta Ricoeur, "uma espera [expectativa] precisa, a de um dizer [parole] que instauraria, entre os antagonistas, uma justa distância que colocaria fim a seu corpo a corpo [isto é, à violência]?" É nessa espera confusa de uma vitória da palavra sobre a violência que consiste, diz ele, a intenção ético-moral da indignação (Cf. Ricoeur, 1995a, p. 12).

Se a transição ou passagem da visada ética à norma moral (a passagem da intenção ao imperativo, do desejo à interdição) é inevitável, é porque a ação implica uma capacidade de fazer que se realiza no plano interativo como poder exercido por um agente sobre um outro. 0 que tem de ser acentuado aqui é 0 fato de que, ao agir, alguém exerce um poder sobre um outro, ou seja, a interação não confronta simplesmente agentes igualmente capazes de iniciativas, mas agentes e pacientes. E é esse poder sobre (outrem) que oferece a ocasião permanente, diz Ricoeur, da

${ }^{8}$ Ver aqui Ricoeur, 1991a, 260. 
violência sob todas as suas formas: "desde a mentira ... até à imposição de sofrimentos, culminando na imposição da morte violenta e na prática horrível da tortura, onde a vontade de humilhar excede a de fazer sofrer" (Ricoeur, 1995a, pp.18-19). O juízo moral sobre a ação deve, então, acrescentar ao predicado bom o predicado obrigatório, geralmente sob a figura negativa do proibido (por exemplo: "Não matarás").

Assim, é a violência - e é essa a tese de Ricoeur - que torna inevitável a passagem da ética à moral; não é o desejo, mas é a violência que nos força a conferir à moralidade o caráter da obrigação, seja sob a forma negativa da proibição, seja sob a forma positiva do mandamento. 0 que Ricoeur já tinha dito antes sobre a indignação encontra aqui uma confirmação e legitimação: o que afinal causa nossa indignação, no caso de divisões, de trocas, ou de retribuições, a não ser o mal (o dano) que os homens causam uns aos outros por ocasião do poder-sobre que uma vontade exerce em relação a uma outra vontade? (Ricoeur, 1995a, p. 19). Mas, se o fato da violência constitui a circunstância maior da passagem do ponto de vista teleológico ao ponto de vista deontológico, esse fato não pode ser considerado como argumento a favor do predicado do obrigatório.

0 que faltava ainda à indignação para ela se igualar a um autêntico sentido da justiça? Segundo Ricoeur, não basta dizer que faltavam ainda os critérios positivos do justo. É necessário identificar o obstáculo que impede a conquista do que ele chamou, como vimos, a justa distância entre os antagonistas das divisões, das trocas e das retribuições que sua indignação denunciava como injustas. Esse obstáculo, diz ele, "é o desejo de vingança, isto é, a pretensão de se fazer justiça por conta própria, mesmo que isso signifique acrescentar a violência à violência, o sofrimento ao sofrimento". A grande conquista, aqui, consistiria em separar vingança e justiça: ao curto-circuito da vingança, a justiça substitui o pôr à distância os protagonistas. Ora, isso só é possível se entra em cena um terceiro que não seria um dos protagonistas.

Uma equação maior - a equação entre justiça e imparcialidade - pode ser agora proposta: justa distância, mediação de um terceiro, imparcialidade se enunciam como os grandes sinônimos do sentido da justiça sobre cujo caminho a indignação conduziu Ricoeur desde quando era muito jovem. É, portanto, sob a condição da imparcialidade que a indignação pode superar o desejo de vingança que incita a vítima a fazer justiça por conta própria (Ricoeur, 1995a, pp. 12-13). Como Ricoeur já disse, ao mencionar a prática judiciária, é na figura do juiz que a justiça se faz reconhecer. Mas, o que liga a imparcialidade do julgamento (do juízo) e a independência do juiz não é justamente a referência à leí? Já estaríamos aqui no centro do ponto de vista deontológico: o que na obrigação obriga, como todos sabem, é a reivindicação de validade universal ligada à idéia de lei (Ricoeur, 1995a, p. 19). 
No oitavo estudo de Soi-même comme un autre - "O si e a norma moral" - Ricoeur procede ao desdobramento das significações implícitas a essa reivindicação de validade universal. Não retomo aqui a argumentação de estilo kantiano que permitiu a Ricoeur, ao concentrar esse estudo sobre a ligação entre obrigação e formalismo, não denunciar apressadamente as fraquezas da moral do dever, mas, ao contrário, dizer sua grandeza, pelo menos tão longe quanto o possa levar um discurso cuja estrutura tripartida duplica exatamente a da visada ética, e que coincide, essencialmente, com as três fórmulas do imperativo kantiano: universalização da máxima da ação, respeito da humanidade em minha pessoa e na de qualquer outro, e instauração de um reino ou ordem dos fins ${ }^{9}$. Limito-me a explicitar, e muito rapidamente, a importante mutação que o sentido da justiça sofre quando transita do ponto de vista teleológico ao ponto de vista deontológico.

É a própria filiação de uma concepção deontológica da justiça - que Ricoeur denomina, com Perelman, de regra de justiça - , a partir do sentido da justiça, que deve, segundo ele, ser fortemente argumentada para podermos ulteriormente compreender "que espécie de recurso 0 sentido da justiça permanece, quando a deontologia se embaraça nos conflitos que ela suscita" (Ricoeur, 1990, p. 264). Para isso, Ricoeur adota - de certo modo "por provisão", diz ele ${ }^{10}$ - a descrição de Rawls, na sua Teoria da Justiça, da sociedade como "um vasto empreendimento de distribuição de bens". Todos esses bens, ou seja, não apenas as remunerações, os patrimônios, os benefícios sociais, mas bens tais como a cidadania, a segurança, a saúde, a educação, e ainda as posições de comando, de autoridade e de responsabilidade no quadro de instituições, constituem problemas de distribuição [des enjeux de distribution]. Ora, a questão aqui consiste em saber se existem divisões desiguais mais justas, ou menos injustas, que outras (cf. Ricoeur, 1995a, pp. 20-21). A solução de Rawls consiste essencialmente, para Ricoeur, em associar o ponto de vista deontológico (de origem kantiana) à tradição contratualista, que oferece 0 quadro de uma ficção, a ficção de uma situação original onde as partes colocadas por hipótese em uma relação mútua de fairness fazem a escolha, entre vários, dos princípios de justiça suscetíveis de ser aceitos por todos.

A tese que Ricoeur propõe para ser discutida, e que ele considera como sendo o segundo teorema de sua teoria do justo [o primeiro teorema era o

\footnotetext{
${ }^{9}$ Ver Ricoeur, 1995a, 20. No plano deontológico da obrigação, o justo identificase ao legal.

10 Ricoeur, 1995a, 20. O termo "por provisão" [par provision] é usado aqui no mesmo sentido em que dizemos que a moral provisória que Descartes formou para si mesmo na terceira parte do Discours de la méthode [1637] é uma moral "par provision", ou seja, é bem mais provisional do que provisória. Ver CALVET de Magalhães, 1996, 8 e 27.
} 
de que o sentido da justiça estaria organicamente ligado ao desejo da vida boa] é a de que o sentido da justiça, elevado ao formalismo que a versão contratualista do ponto de vista deontológico requer, não pode tornar-se inteiramente autônomo ou independente de toda referência ao bem, devido à natureza do problema posto pela idéia de distribuição justa, a saber levar em consideração a heterogeneidade real dos bens a distribuir. Ou dito de outro modo: "o nível deontológico ... não pode se autonomizar ao ponto de constituir o nível exclusivo de referência" (Ricoeur, 1995a, p. 21).

Tanto em Soi-même comme un autre como em Le Juste, Ricoeur mostra a impossibilidade de fundar uma teoria puramente procedimental da justiça, ou mostra os limites de uma abordagem deontológica da justiça, ao se apoiar sobre três constatações:

1) em primeiro lugar, os dois princípios da justiça de Rawls pressupõem uma certa compreensão do justo tributária das visadas particulares de cada parte, isto é, do que elas consideram bom ou mau para elas e para os outros;

2) subsistem ainda conflitos que nenhuma regra de procedimento nem nenhum acordo permitiria negociar tão facilmente; e

3) finalmente, a distância ou separação que permanece entre esses princípios e a prática, entre a regra e 0 juízo em situação concreta, não é abolida ${ }^{11}$.

Mas se Ricoeur insiste em mostrar que o justo encontra-se "entre o legal e o bom", não se trata simplesmente para ele de opor o deontológico ao teleológico, ou Kant a Aristóteles, mas de mostrar que a ética passa pelo formalismo e que, de modo inverso, o formalismo não pode se subtrair a uma representação do bem. Ricoeur não afirma apenas o primado da ética, mas reconhece ao mesmo tempo que a visada ética deve passar pelo crivo da norma. A lei (a norma moral) é, segundo ele, um momento indispensável da ética, do esforço de "viver bem", mas não resume por si só a vida ética. Ou seja, o momento deontológico deve ele mesmo conhecer seus limites e baixar ou diminuir suas pretensões.

Um certo recurso da norma moral à visada ética é sugerido então pelos conflitos que nascem da própria aplicação das normas a situações concretas:

"Sabemos desde a tragédia grega, e singularmente desde a Antígona de Sofocles, que conflitos nascem precisamente quando caracteres obstinados ... se identificam tão inteiramente a uma regra particular que tornam-se cegos

11 Ver aqui AвEL, 1996, 76. 
em relação a toda outra regra: (...). Guerra dos valores ou guerra dos engajamentos fanáticos", o resultado para Ricoeur é sempre o mesmo, a saber: "o nascimento de um trágico da ação sobre o fundo de um conflito de dever" (Ricoeur, 1991a, p. 265).

E é para fazer face a esse tipo de situações que é exigida uma sabedoria prática,

"uma sabedoria ligada ao juízo moral em situação e para à qual a convicção é mais decisiva que a própria regra. Essa convicção não é, contudo, arbitrária, na medida em que recorre a recursos do sentido ético o mais originário que não passaram para a norma" (Ricoeur, 1991a, p. 265).

A conviç̧ão compensaria o que uma "ética do discurso", por exemplo, tem de cerebral: as convicções também podem ser pesadas, avaliadas, argumentadas, comparadas, criticadas (e é justamente o que as distingue de meros preconceitos), mas não são, no entanto, totalmente explicitáveis. A convicção emana de sujeitos que são também corpos, ou seja, corpos que sofrem, que desejam, que falam, que agem, e esses corpos permanecem os pontos de apoio de nossas iniciativas e de nossas responsabilidades. Essa corporeidade marca para Ricoeur a finitude de nossa convicções, sua singularidade.

0 justo qualifica, em última instância, uma decisão singular tomada em um clima de conflito e de incerteza. Ricoeur admite, assim, que a discórdia é uma estrutura fundamental da relação inter-humana. Ele afirma ser contra o angelismo, mesmo sob sua forma racionalista, a que corre o risco de ceder uma apologia do consenso sem dissenso na linha da ética do discurso tão cara a Habermas (Changeux e Ricoeur, 1998, pp. 334-335).

A experiência histórica mostra, diz Ricoeur, "que não há regra imutável para classificar numa ordem universalmente convincente reivindicações tão estimáveis como as da segurança, da liberdade, da legalidade, da solidariedade, etc...". Só o debate público, insiste ele, "cujo desfecho permanece aleatório, pode criar ou fazer surgir uma certa ordem de prioridade" - mas essa ordem "só valerá para um povo, durante um certo período de sua história, sem nunca alcançar uma convicção irrefutável válida para todos os homens e para todos os tempos". 0 juízo político é, então, também da ordem do juízo em situação. Pode ser, com mais ou menos sorte, o lugar da sabedoria, do "bom conselho" que o coro de Antígona evoca. Mas essa sabedoria prática já não é um assunto pessoal: trata-se, por assim dizer, de uma phronesis pública como o próprio debate. A eqüidade é aqui "um outro nome do sentido da justiça, quando este atravessou os conflitos suscitados pela própria aplicação da regra de justiça" (Ricoeur, 1991a, p. 268). No plano da sabedoria prática, 0 justo não é mais nem o bom nem o legal: é 0 eqüitativo. 
O terceiro teorema da concepção do justo, desdobrada por Ricoeur em Le Juste, seria o de que o sentido da justiça, que permanece enraizado no desejo da vida boa e que encontra sua formulação racional a mais ascética no formalismo procedimental, só atinge sua plenitude concreta no momento da aplicação da norma no exercício do juízo em situação (Ricoeur, 1995a, p. 26).

\section{A prática da justiça (a prática judiciária)}

Se a reflexão de Ricoeur sobre o justo encontrou na instituição judiciária a sua referência privilegiada, é porque podemos aí, a esse nível, ler claramente "a exigência de conduzir a idéia do justo até à fase final do processo, onde o direito é dito aqui e agora" (Ricoeur, 1995a, p. 25). Cairemos, contudo, no erro inverso ao do que diz respeito à exclusividade do formalismo, conclui Ricoeur, "se a problemática da aplicação da norma for considerada não apenas como menor, mas como insignificante aos olhos de uma teoria jurídica digna desse nome". Pode-se chegar ou ser conduzido a essa depreciação errônea, segundo ele, "seja por uma concepção puramente mecânica da aplicação da norma a um caso, seja por uma concepção discricionária do pronunciamento da sentença". Toda a problemática, que Ricoeur qualifica por meio do adjetivo "phronétique" consiste então "em explorar a zona média onde o juízo se forma, a meio caminho da prova, submetida à coerção lógica, e do sofisma, motivado pelo gosto de seduzir ou pela tentação de intimidar". Dependendo das estratégias envolvidas, essa "zona média" pode ser designada de várias nomes: retórica, hermenêutica, poética (Ricoeur, 1995a, p. 25).

Do ponto de vista lógico, o discurso da justiça ilustra muito bem o lugar que a argumentação ocupa: a meio caminho (a justa distância, ousa dizer Ricoeur) entre a prova (ou o discurso demonstrativo) e o uso sofístico da linguagem (ou a violência dissimulada no discurso de pura sedução). É claro que, num processo, é pedido que se forneçam provas, provas materiais e testemunhos irrecusáveis, mas o processo, considerado como um todo, não é da ordem da prova, ou seja, não é da ordem da necessidade lógica. $M$ as isso não significa condenar a argumentação jurídica ao sofisma. Atingimos aqui, diz ele, o ponto de fragilidade que 0 discurso judiciário tem em comum com outros tipos de discursos (o discurso político, mas também o discurso do historiador, do editorialista, do historiador do presente). Fragilidade, portanto, de um discurso que, se não prova, visa contudo a convencer, sem se reduzir a meramente agradar. Esse estatuto epistemológico é, segundo Ricoeur, 
o da lógica do provável, expressão com a qual Aristóteles definia a dialética e à qual ele ligava a retórica ou "a arte de usar argumentos prováveis no uso público da fala" (Ricoeur, 1991b, pp. 194-195).

Trata-se, assim, no caso do processo, do que Ricoeur considera como um funcionamento muito específico da racionalidade, que é o da retórica, no sentido forte dessa palavra, ou seja, "como o que se opõe o mais nitidamente à sofística, como implicando o uso de raciocínios prováveis e de natureza controvertível". Por um lado, num processo, o "confronto" de argumentos [l'assaut d'arguments] é infinito, já que, nessa região da racionalidade, ou seja, na ordem do provável, "há sempre lugar para um "mas" - sob a forma, por exemplo, de recurso e de vias de apelação a instâncias superiores". Mas, por outro lado, esse confronto é finito: "o conflito de argumentos termina com uma decisão, a saber: o julgamento exercido em uma situação particular"12. Ou seja, este primeiro círculo jurídico ou o "judiciário do direito" constitui "uma região de racionalidade intermediária, onde 0 pressuposto é justamente 0 corte entre discurso e violência". O lugar da justiça está, assim, marcado "como fazendo parte do conjunto das alternativas que uma sociedade opõe à violência e que todas juntas definem um Estado de direito" (Ricoeur, 1995a, p. 189).

À finalidade curta do "ato de julgar" [l'acte de juger], no sentido judiciário desta palavra ("estatuir na qualidade de juiz"), que consiste em decidir [trancher], ou seja, em separar as partes, Ricoeur opõe uma finalidade longa, talvez mais dissimulada, a saber, a contribuição do julgamento à paz pública:

"o horizonte do ato de julgar é finalmente mais que a segurança, a paz social. (...) A finalidade da paz social faz aparecer em filigrana algo de mais profundo que diz respeito ao reconhecimento mútuo. (...) Mas em que sentido? Penso que 0 ato de julgar atingiu seu fim quando aquele que, como se diz, ganhou seu processo sente-se ainda capaz de dizer: meu adversário, aquele que perdeu, permanece como eu um sujeito de direito; a sua causa merecia ser ouvida; ele tinha argumentos plausíveis... . Mas o reconhecimento só seria completo quando a coisa pode ser dita por aquele que perdeu, ... o condenado; ele deveria poder declarar que a sentença ... não era um ato de violência mas de reconhecimento" (Ricoeur, 1995a, pp. 190-191).

Haveria, então, um lugar onde é a palavra que ganha, e não a violência. Foi, portanto, o jurídico, apreendido sob os traços do judiciário, que permitiu a Ricoeur uma reflexão sobre a especificidade do direito, a meiocaminho da moral e da política. Em Le Juste, para dar um tom dramático à oposição que ele faz entre uma filosofia política e uma filosofia do direito, Ricoeur afirma que a guerra é o tema lancinante da filosofia política, e a paz o tema da filosofia do direito (Ricoeur, 1995a, p. 10).

12 Cf. Ricoeur, 1995a, 187, e 1991b, 195. 
Referindo-se mais especificamente à ordem política, e não mais à instância judiciária, Ricoeur constata que em certos casos, a paz pública pode implicar uma forma institucionalizada da amnésia - a anistia. 0 preço a pagar por essa verdadeira amnésia institucional é alto demais: todos os perigos que o esquecimento apresenta estariam contidos "nessa pretensão inacreditável de apagar os vestígios das discórdias públicas". Cabe então, neste caso, ao historiador a difícil tarefa (uma tarefa de certo modo subversiva) de confrontar pelo discurso, o que não é, segundo Ricoeur, outra coisa a não ser "a tentativa pseudo-jurídica de apagamento dos fatos" (Ricoeur, 1995a, p. 206).

\section{Referências bibliográficas}

ABEL, Olivier. Paul Ricoeur, La promesse et la règle, Paris, M ichalon, 1996.

CALVET DE MAGALHÃES, Theresa. 1996. A generosidade como uma forma de conhecimento: a moral na filosofia de Descartes, Ética e Filosofia Política v. 1, no 1, 7-40.

CHANGEUX, Jean Pierre - RICOEUR, Paul. Ce qui nous fait penser. La nature et la règle. Paris, O dile Jacob, 1998.

RICOEUR, Paul. Soi-même comme un autre, Paris, Seuil, 1990.

RICOEUR, Paul. Éthique et morale, Lectures 1: Autour du politique. Paris, Seuil, 1991a, 256-269.

RICOEUR, Paul, Le juste entre le légal et le bon, Lectures 1: Autour du politique. Paris, Seuil, 1991b, 176-195.

RICOEUR, Paul. Le Juste. Paris, Esprit, 1995a.

RICOEUR, Paul. La critique et la conviction. Entretien avec François Azouvi e Marc de Launay. Paris, Calmann-Lévy, 1995b.

VAZ, Henrique C. de Lima. Escritos de Filosofia II: Ética e Cultura. São Paulo, Loyola, 1988. 